\title{
Exploring the relationship among polarity, subjectivity, and clusters characteristics of visitor review on tourist destination in Malang, Indonesia
}

\author{
A. Larasati*, M. Farhan, P. Rahmawati, J. Sayono \& A. Purnomo \\ Universitas Negeri Malang, Indonesia \\ E. Mohamad \\ Universiti Teknikal Malaysia Melaka, Malaysia
}

\begin{abstract}
The development of information technology has made it easier for various people activities. One of them is the development of information technology in the tourism sector, where information and access to deliver opinions or reviews on tourist attractions are available on various websites and social media. This study aims to explore the relationships among polarity, subjectivity, and clusters characteristics of online tourist reviews on different tourist objects in the Malang Regency. Online-review data was retrieved using the web content mining technique. The study applies sentiment analysis and k-mean clustering to analyze retrieved online-review data. The clustering process was performed to classify existing reviews based on their respective characteristics using the k-means clustering algorithm. The results show a significant difference between clusters and sentiment of the visitor reviews on each tourist object. The sentiment analysis results also indicate differences in the interpretation of polarity and subjectivity in each cluster at the same objects. The results of each tourist object's clusters and sentiment show that the review of the services and objects offered tends to be a positive sentiment. On the other hand, the reviews for the facilities offered, the visitors' reviews tend to be neutral. For the negative sentiment, it mostly occurs about the price as well as the location of the tourist objects.
\end{abstract}

\section{INTRODUCTION}

The sentiment is one of the most important things for any company or business. Sentiment analysis can help see feelings, needs, and patterns of customer responses to the product or service being offered (Syakuyaqubr et al. 2018). In sentiment analysis, two parameters are used as measurement benchmarks, namely the polarity and subjectivity values generated from online reviews delivered by customers. Polarity shows whether the reviews contain positive, neutral, or negative feelings. Meanwhile, subjectivity points out whether the responses can be classified as visitors' opinions or not. In terms of polarity, the higher the value generated increases the likelihood of the positive responses, while higher subjectivity indicates that the review given is an opinion. Various techniques can be used to perform sentiment analysis, for example, using machine learning. Machine learning can determine the pattern of comments given by visitors to help managers understand the needs of visitors and their feelings (Syakur et al. 2018).

The clustering process aims to see the grouping of reviews in each tourist destination using $\mathrm{K}$-means. It is the most commonly used algorithm in clustering because of its simplicity of use. The advantage of the K-means method is its effective use on large amounts of data. However, the $\mathrm{K}$-means method has limitations in determining the best number of clusters. This limitation is in

*Corresponding author: aisyah.larasati.ft@um.ac.id 


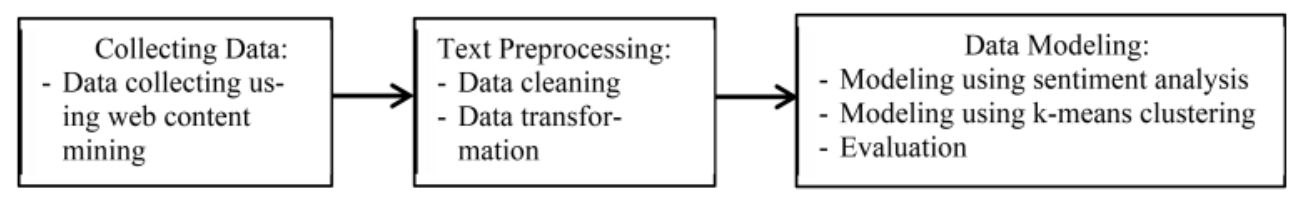

Figure 1. Research methods (collecting data, text processing, and data modeling).

the form of the final cluster result, which is very dependent on determining the center of the cluster (centroid) at the beginning of the process. Thus this algorithm is considered to have high sensitivity because the determination of the centroid's starting point has an impact on the final cluster results (Syakur et al. 2018).

This study aims to explore the relationship between clustering and sentiment (polarity and subjectivity) from online reviews given by visitors of tourist destinations in the Malang Regency. The polarity and subjectivity results obtained were linked to the characteristics of the cluster formed. Online reviews were obtained by implementing web content mining at each tourist destination. Web content mining works by indexing information in the form of text, audio, images, HTML, XML, which consists of structured, semi-structured, and non-structured data types (Mebrahtu \& Srinivasulu 2017). The advantage of web content mining is the capability to change unstructured data into structured data easily understood by humans.

Sentiment analysis is a technique used to identify and classify the polarity and subjectivity of a text (Ankit \& Saleena 2018). The process of sentiment analysis uses Natural Language Processing (NLP) works by assessing the emotional tendency of a word or sentence (Drus \& Khalid 2019). Polarity analysis is useful to determine whether the opinion falls into the positive, neutral, or negative category. In polarity analysis, the words in the lexicon are weighted with a score ranging from -1 for negative sentiment, 0 representing neutral sentiment, and +1 for the positive sentiment (Drus \& Khalid 2019). Within the scope of sentiment analysis, there are stages of subjectivity analysis. Subjectivity analysis is the process of classifying an opinion as a subjective opinion or an objective word of fact. In the sentiment analysis, words are scored with a 0 to 1 score; a score close to 1 means the text is subjective, while a score close to 0 represents objective opinion (Yaqub et al. 2018). Sentiment analysis is useful and widely applied in various fields such as e-commerce, tourism, health, manufacturing, and various other industries (Irawan et al. 2019). The existence of sentiment analysis can be a reference for business managers in making continuous improvements to a business object's facilities and services.

\section{METHODS}

The method of this study is shown in Figure 1. Data was extracted from online visitor reviews on five tourist objects in Malang Regency available on various websites. The tourist objects were Masjid Turen, Bedengan, Pantai Tiga Warna, Kebun Teh Wonosari, and Lembah Indah. The total number of reviews obtained was 4269 data, but only 2170 data were analyzed after the text preprocessing phase.

The process of collecting visitor reviews on each tourist attraction used web content mining technology. Web content mining is a part of the web mining field that can be used for collecting unstructured data sourced from websites by accessing the specific HTML elements of the data (Slamet et al. 2018). The web content mining process was started with selecting web page URL, namely websites of tourist attractions in Malang, which have visitor reviews. Web content mining can process data in multiple web pages at one time, thereby increasing time efficiency while retrieving the data. The retrieved data was used as data input in undertaking the analysis process by applying data mining techniques, including text mining and sentiment analysis, to attain new insight as a fundamental for better decision making (Hassani et al. 2020). 


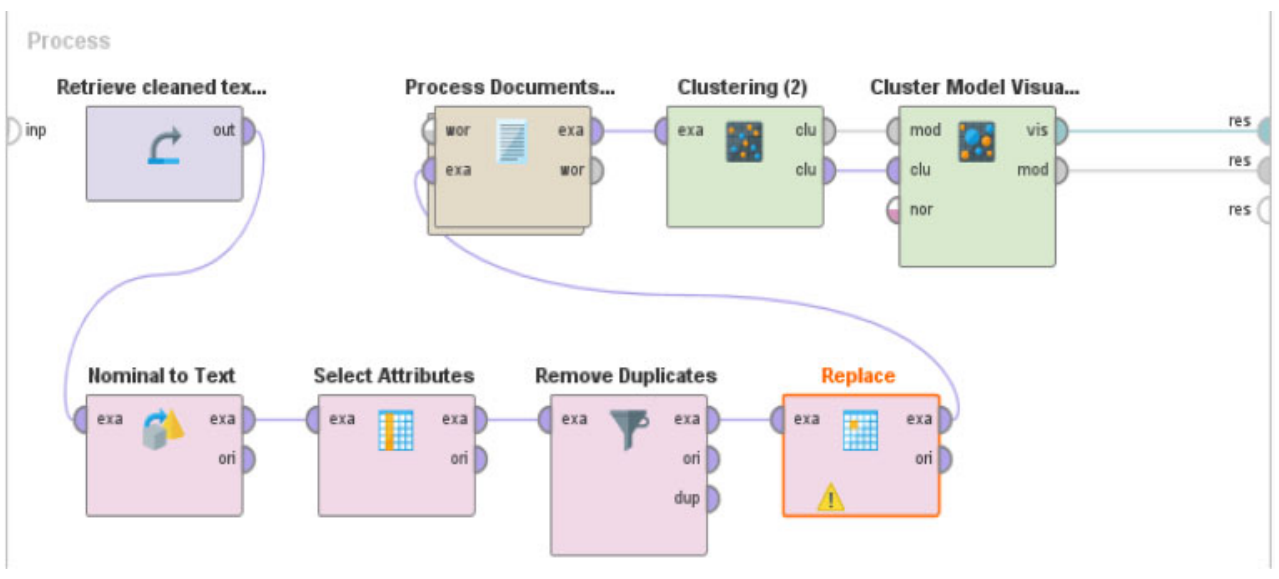

Figure 2. Text preprocessing and K-means clustering in Rapid Miner.

After collecting data, the text preprocessing was carried out. This method transforms text data into a numerical format based on the vector dimensions that are formed in each composing word. After all the text preprocessing steps had been completed, the files were saved in excel form. Then the process of Sentiment Analysis and K-means clustering was continued by utilizing Rapid Miner.

The outcomes of K-means were further evaluated by considering the polarity and subjectivity values of Sentiment Analysis to discover and determine whether there was a correlation among polarity, subjectivity and cluster characteristics. The detailed steps from text preprocessing to K-means algorithm implementation in Rapid Miner are shown in Figure 2.

\section{RESULTS AND DISCUSSION}

The following is the result of data processing with 2170 reviews extracted from five tourist objects within the Malang Regency. In the clustering process, the number of clusters was determined by 5 clusters. The evaluation of clustering results was carried out by calculating the Davies-Bouldin Index (DBI) score. The best cluster results are shown in the smaller DBI score. The wordlists are displayed in the table covering the top 5 rankings on visitors' reviews of tourist objects.

\subsection{Masjid Turen}

Table 1 denotes the characteristics and sentiment in each cluster with 532 reviews obtained from the websites related to the tourist object of Masjid Turen. The value of the Davies Bouldin Index for the cluster is 2.69 . Referring to polarity for discovering sentiment categories and subjectivity to ensure either fact or opinion in each review, visitors tend to give positive reviews based on their views and experiences, with the overall percentage being $87.4 \%$. In contrast, the rest of the visitors tend to deliver neutral reviews. There are no negative sentiments given by visitors.

\subsection{Bedengan}

Table 2 denotes the characteristics and sentiment in each cluster with 389 reviews obtained from the websites.

The value of the Davies Bouldin Index for the cluster shown in Table 2 is 4.76. Referring to polarity for discovering sentiment categories and subjectivity for ensuring either fact or opinion in each review, visitors tend to give positive reviews based on their opinions and experiences. The overall percentage is $61.95 \%$. Besides, the percentage of negative sentiments and neutral sentiments is $22.62 \%$ and $15.42 \%$, respectively. 
Table 1. Cluster characteristics of Masjid Turen.

\begin{tabular}{llcclc}
\hline & \multicolumn{2}{l}{ Wordlist Occurrences } & \multicolumn{2}{c}{ Stemming } \\
\cline { 2 - 6 } No & Wordlist & Total Occurrences & Total items in each cluster & Characteristics & Sentiment \\
\hline 1 & Mosque & 887 & 67 & Tourism, religion, floor & Neutral \\
2 & Building & 202 & 183 & Build, School, Tourist & Positive \\
3 & Beautiful & 132 & 84 & Board. School, tourism & Positive \\
4 & Cool & 108 & 118 & Cool, place, good & Positive \\
5 & Unique & 90 & 80 & Unique, religious, tourism & Positive \\
\hline
\end{tabular}

Table 2. Cluster characteristics of Bedengan.

\begin{tabular}{llcccc}
\hline & \multicolumn{2}{l}{ Wordlist Occurrences } & \multicolumn{2}{c}{ Stemming } \\
\cline { 2 - 6 } No & Wordlist & Total Occurrences & Total items in each cluster & Characteristics & Sentiment \\
\hline 1 & Place & 228 & 88 & Car, malang, unfortune & Negative \\
2 & Cool & 152 & 113 & Fresh, recommend, nature & Positive \\
3 & Natural & 102 & 59 & Picnic, Suitable, Family & Positive \\
4 & Beautiful & 81 & 69 & Comfort, Relax, beauty & Positive \\
5 & Good & 68 & 60 & Tree, flow, pine & Neutral \\
\hline
\end{tabular}

Table 3. Cluster characteristics of Pantai Tiga Warna.

\begin{tabular}{llcclc}
\hline & \multicolumn{2}{c}{ Wordlist Occurrences } & \multicolumn{2}{c}{ Stemming } \\
\cline { 2 - 6 } No & Wordlist & Total Occurrences & Total items in each cluster & Characteristics & Sentiment \\
\hline 1 & Beach & 905 & 166 & Great, fun & Positive \\
2 & Beautiful & 165 & 19 & Difficult, access, look & Negative \\
3 & Clean & 143 & 66 & Beauty paid, suitable & Positive \\
4 & Good & 127 & 66 & Number, day, people & Neutral \\
5 & Trash & 88 & 75 & Ojek, taxi, clungup & Neutral \\
\hline
\end{tabular}

\subsection{Pantai Tiga Warna}

Table 3 denotes the characteristics and sentiment in each cluster with 392 reviews obtained from the websites. The value of the Davies Bouldin Index for clustering is 4.8. Referring to polarity for discovering sentiment categories and subjectivity to ensure either fact or opinion in each review, visitors tend to give positive reviews based on their opinions and experiences, with the overall percentage being $59.18 \%$. In addition, the rate of negative sentiments and neutral sentiments are $4.84 \%$ and $35.96 \%$, respectively.

\subsection{Kebun Wonosari}

Table 4 denotes the characteristics and sentiment in each cluster with 575 reviews obtained from the websites. The value of the Davies Bouldin Index for the cluster is 3.08. Referring to polarity for discovering sentiment categories and subjectivity for ensuring either fact or opinion in each review, visitors tend to give positive reviews based on their opinions and experiences. The overall positive review percentage is $75,13 \%$, while the rest is neutral reviews. 
Table 4. Cluster characteristics of Kebun Wonosari.

\begin{tabular}{llcclc}
\hline & \multicolumn{2}{c}{ Wordlist Occurrences } & \multicolumn{2}{c}{ Stemming } \\
\cline { 2 - 6 } No & Wordlist & Total Occurrences & Total items in each cluster & Characteristics & Sentiment \\
\hline 1 & Tea & 665 & 116 & Air, comfort, suitable & Positive \\
2 & Garden & 301 & 140 & Pool, swim, children & Positive \\
3 & Good & 159 & 103 & Good, view, nice & Positive \\
4 & Beautiful & 130 & 143 & Wonosari, tea, gardern & Neutral \\
5 & Fresh & 67 & 73 & Spot, photo, tourist & Positive \\
\hline
\end{tabular}

Table 5. Cluster characteristics of Lembah Indah.

\begin{tabular}{llcclc}
\hline & \multicolumn{2}{c}{ Wordlist Occurrences } & \multicolumn{2}{c}{ Stemming } \\
\cline { 2 - 6 } No & Wordlist & Total Occurrences & Total items in each cluster & Characteristics & Sentiment \\
\hline 1 & Cool & 135 & 76 & Air, family, cool & Positive \\
2 & Good & 98 & 42 & Ticket, prie, facility & Neutral \\
3 & Beautiful & 90 & 74 & Tourist, Malang, facility & Positive \\
4 & Nice & 45 & 39 & Photo, spot, good & Positive \\
5 & Natural & 35 & 51 & Nice, view, place & Positive \\
\hline
\end{tabular}

\subsection{Lembah Indah}

Table 5 denotes the characteristics and sentiment in each cluster with 282 reviews obtained from the websites. The value of the Davies Bouldin Index for the clusters is 2.683. Referring to polarity for discovering sentiment categories and subjectivity for ensuring either fact or opinion in each review, visitors tend to give positive reviews based on their opinions and experiences, with the overall percentage are $85.1 \%$, while the rest tend to deliver neutral reviews.

Based on the results shown in Tables 1-5, each tourist attraction has different cluster characteristics. These characters may reflect the visitors' tendency. The expressions delivered by visitors can be in the form of evaluations or their experiences and descriptions related to the tourist objects visited. The cluster characteristics depend on the wordlist and its occurrences, which are derived from the web scrapping process. Web scraping is the process of extracting, collecting, and storing data sourced from the internet into a database (Dewi et al. 2019). The web scraping process has various advantages, such as it is easy and does not require much data processing time. Besides, the web scraping process can also convert unstructured data into structured forms such as spreadsheets and CSV. The existence of web scraping helps in various aspects, for example, identify web changes, competitor analysis, stock prices, market data, weather data, and so forth (Saurkar \& Gode 2018). Therefore, this process is considered to contribute to business processes when making optimal decisions based on data, including extracting cluster characteristics.

\section{CONCLUSION}

The data processing results on five tourist objects reveal a significant difference between clusters and sentiment of the visitor reviews on each tourist object. The DBI calculation results show that the clusters resulted for Bedengan and Pantai Tiga Warna are worse than the others. The characteristics of the words that appear in each cluster also have significant differences between each tourist object. The sentiment analysis conducted shows differences in the interpretation of polarity and subjectivity in each cluster at the same objects. Thus, to improve tourist visits, tourist management 
may focus on clusters that deliver negative sentiments while maintaining good service for clusters that deliver positive reviews.

\section{REFERENCES}

Ankit, Saleena, N., 2018. An Ensemble Classification System for Twitter Sentiment Analysis. Procedia Computer Science 132, 937-946. https://doi.org/10.1016/j.procs.2018.05.109

Dewi, L.C., Meiliana, Chandra, A., 2019. Social media web scraping using social media developers API and regex. Procedia Computer Science 157, 444-449. https://doi.org/10.1016/j.procs.2019.08.237

Drus, Z., Khalid, H., 2019. Sentiment analysis in social media and its application: Systematic literature review. Procedia Computer Science 161, 707-714. https://doi.org/10.1016/j.procs.2019.11.174

Hassani, H., Beneki, C., Unger, S., Mazinani, M.T., Yeganegi, M.R., 2020. Text mining in big data analytics. Big Data and Cognitive Computing 4, 1-34. https://doi.org/10.3390/bdcc4010001

Irawan, H., Akmalia, G., Masrury, R.A., 2019. Mining tourist's perception toward Indonesia tourism destination using sentiment analysis and topic modelling. ACM International Conference Proceeding Series 7-12. https://doi.org/10.1145/3361821.3361829

Mebrahtu, A., Srinivasulu, B., 2017. Web Content Mining Techniques and Tools. International Journal of Computer Science and Mobile Computing 6, 49-55.

Saurkar, A. V, Gode, S.A., 2018. An Overview On Web Scraping Techniques And Tools. International Journal on Future Revolution in Computer Science \& Communication Engineering 363-367.

Slamet, C., Andrian, R., Maylawati, D.S., Suhendar, Darmalaksana, W., Ramdhani, M.A., 2018. Web Scraping and Naïve Bayes Classification for Job Search Engine. IOP Conference Series: Materials Science and Engineering 288. https://doi.org/10.1088/1757-899X/288/1/012038

Syakur, M.A., Khotimah, B.K., Rochman, E.M.S., Satoto, B.D., 2018. Integration K-Means Clustering Method and Elbow Method for Identification of the Best Customer Profile Cluster. IOP Conference Series: Materials Science and Engineering 336. https://doi.org/10.1088/1757-899X/336/1/012017

Yaqub, U., Sharma, N., Pabreja, R., Chun, S.A., Atluri, V., Vaidya, J., 2018. Analysis and visualization of subjectivity and polarity of twitter location data. ACM International Conference Proceeding Series. https://doi.org/10.1145/3209281.3209313 